This preliminary note is published with the permission of the Royal Society. In a later more detailed account, it will be possible to make proper acknowledgments to those who have assisted in the measurements and in the preliminary work.

E. C. Bullard.
T. F. Gaskell.

Dept. of Geodesy and Geophysics,

University, Cambridge. Sept. 27.

Oxygen Isotopic Exchange in Animal Respiration

OXYGEN enriched with respect to ${ }^{18} \mathrm{O}$ has been used to solve the problem of how far oxygen, expired by an animal in the form of carbon dioxide, is identical with that inspired as molecular oxygen. Using rats, and an artificial atmosphere containing oxygen equivalent in isotopic composition to water of 300 p.p.m. excess density, it was found that the expired carbon dioxide, which was dried and collected by refrigeration methods, contained oxygen isotopes in proportions corresponding to water with about 40 p.p.m. excess density, the error of measurement being 2 p.p.m. As the quantity of oxygen absorbed by the animal during each preliminary sweep-out was considerably greater than the total oxygen and carbon dioxide stored as oxy-hæmoglobin or bicarbonate, it can be accepted that the experimental results refer to the steady state.

The two possibilities usually considered with regard to the fate of respiratory oxygen are : (1) it enters directly into carbon oxidation and is exhaled as carbon dioxide; (2) it enters into combination with the hydrogen of water, the originally combined oxygen of which effects carbon oxidation and appears as carbon dioxide. Our results show that mechanism (1) operates, since (2) acting alone would lead to an almost complete absence of inspired oxygen from the expired carbon dioxide. The fact that only a proportion of the inspired oxygen reappears may be due to oxygen exchange between water and carbon dioxide produced by mechanism (1); or it may be due to the incursion of mechanism (2).

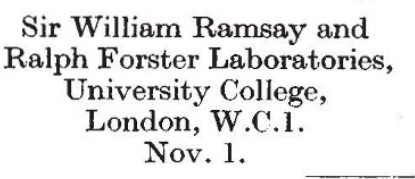

J. N. E. DAY. P. Sheel.

\section{Induced Tetraploidy in Melandrium album}

In the flowering plants, the problem of polyploidy in relation to diœcism is an extraordinarily attractive one, since it should be possible in this way to get additional proof of the balance theory of sex determination.

So far, experimentally produced polyploids have not been described in diœcious plants, but occasionally such forms have been found in Nature. In Rume $x^{1,2}$, triploids, tetraploids and a hexaploid have been described; in Vallisneria ${ }^{3}$ and Empetrum ${ }^{4}$, tetraploids are known to occur. These polyploids, which are considered by the authors to be of autopolyploid origin, are in Rumex intersexual, in Empetrum bisexual and in Vallisneria diœeious, as in the diploid form.

In Melandrium album, diœeism is very clear-cut. The male sex is heterogamous, having 11 pairs of autosomes and one pair of $X Y$ chromosomes, the $X$ chromosome being considerably larger than the $Y$ and larger than any of the autosomes. The female plants are homogamous, having 11 pairs of autosomes and $2 X$ ehromosomes ${ }^{5,6}$.

Tetraploids have been induced in Melandrium album in the summer of this year by the method of Randolph ${ }^{7}$ as well as by the colchicine method ${ }^{8}$. The tetraploid plants differ little from the diploids in appearance, and are very difficult to pick out. Their leaves are somewhat thicker, the hairiness more conspicuous and the flowers relatively large. Only chromosome counts can tell us the true nature of the suspected plants, and so far ten plants (out of $1,700)$ have proved to be tetraploid.

These tetraploids are interesting from several points of view. First concerning the sex expression. The tetraploid plants show a diœecism just as clear-cut as that of the diploids; the $X X X X$ plants are females, the $X X Y Y$ plants are males (six of the ten tetraploids were males, four were females). Secondly, concerning the meiosis in tetraploid males, a preliminary investigation has shown that the most frequent conjugation type of the sex chromosomes is autosyndesis, that is, $X-X$ and $Y-Y$ chromosomes pair. Less frequently the sex chromosomes conjugate $X-Y$ and $X-Y$. The first mode of conjugation will give rise to gametes containing two sets of autosomes $(2 A)$ an $X$ - and a $Y$-chromosome $(2 A+X+Y)$. The second mode will produce gametes of three sorts : $(2 A+2 X),(2 A+X+Y)$ and $(2 A+2 Y)$ in the theoretical ratio $1: 4: 1$, as previously postulated by H. J. Muller ${ }^{9}$. A considerable excess of gametes of the formula $(2 A+X+Y)$ will result. As the females by normal chromosome separation will produce egg-cells of the type $(2 A+2 X)$ only, three types of plants should appear by breeding tetraploids with tetraploids, if all types of gametes are viable, the plants being of the formulæ $(4 A+4 X)$, $(4 A+2 X+2 Y)$ and $(4 A+3 X+Y)$. It may further be mentioned that it is possible to cross tetraploids with diploids, both in the direction tetraploid female $\times$ diploid male, and the opposite way. This should give rise to three types of triploids, containing the chromosome sets $(3 A+3 X),(3 A+2 X+Y)$ and $(3 A+X+2 Y)$. Thus the polyploid Melandrium should furnish very promising material for the study of sex balance.

Laboratory of Genetics,

Royal Veterinary and Agricultural College, Copenhagen.

${ }^{1}$ Ono, T., and Shimotomai, N., Bot. Mag., 42, 269 (1928)

? Yamamoto, Y., Jap. J. Gen., 11, 6 (1935).

${ }^{3}$ Jørgensen, C. A., J. Gen., 18, 63 (1927).

${ }^{4}$ Hagerup, O., Dansk bot. Arkiv, 5, 1 (1927).

s Blackburn, K. B., Nature, 112, 687 (1923).

- Winge, Ø., C.R. Trav. Lab. Carlsberg, 11, 1 (1923).

' Randolph, L. F., Proc. Nat. Acad. Sci., 18, 222 (1932).

Blakeslee, A. F., and Avery, A. G., J. Heredity, 28, 393 (1937).

- Muller, H. J., Amer. Nat., 59, 346 (1925).

\section{Control of Four Smut Diseases by Regulation} of Planting Method under Irrigation

ANomalous amounts of disease in supposedly exactly repeated experiments of flag smut of wheat, and previously with covered smut of barley ${ }^{1}$, were eventually traced to difference in planting method. Under irrigation in Egypt, these cereals are either broadcast on moist land and ploughed in (herati method) or broadcast on dry land, harrowed in with a wooden baulk and irrigated (afir method). 